\title{
Seasonal Dynamics of Glyphosate and AMPA in Lake Greifensee: Rapid Microbial Degradation in the Epilimnion During Summer
}

\author{
Sebastian Huntscha, ${ }^{\dagger}$ Michael A. Stravs, ${ }^{\ddagger, \S}$ Andreas Bühlmann, ${ }^{\dagger}$ Christian H. Ahrens, ${ }^{\dagger}, \|$ Jürg E. Frey, ${ }^{\dagger}$ \\ Francesco Pomati, ${ }^{\ddagger} \perp$ Juliane Hollender, ${ }^{\ddagger}, \S$ Ignaz J. Buerge, ${ }^{\dagger}$ Marianne E. Balmer, ${ }^{\dagger}$ \\ and Thomas Poiger*, (1)
}

\author{
${ }^{\dagger}$ Agroscope, Schloss 1, 8820 Wädenswil, Switzerland \\ ${ }^{\ddagger}$ Eawag, Swiss Federal Institute of Aquatic Science and Technology, 8600 Dübendorf, Switzerland \\ ${ }^{\S}$ ETH Zurich, Institute of Biogeochemistry and Pollutant Dynamics, 8092 Zürich, Switzerland \\ ${ }$ Swiss Institute of Bioinformatics (SIB), Schloss 1, 8820 Wädenswil, Switzerland \\ ${ }^{\perp}$ ETH Zurich, Institute for Integrative Biology, 8092 Zürich, Switzerland
}

\section{Supporting Information}

ABSTRACT: Occurrence and fate of glyphosate, a widely used herbicide, and its main metabolite AMPA was investigated in Lake Greifensee, Switzerland. Monthly vertical concentration profiles in the lake showed an increase of glyphosate concentrations in the epilimnion from $15 \mathrm{ng} / \mathrm{L}$ in March to $145 \mathrm{ng} / \mathrm{L}$ in July, followed by a sharp decline to $<5 \mathrm{ng} / \mathrm{L}$ in August. A similar pattern was observed for AMPA. Concentrations of glyphosate and AMPA in the two main tributaries generally were much higher than in the lake. Simulations using a numerical lake model indicated that a substantial amount of glyphosate and AMPA dissipated in the epilimnion, mainly in July and August, with half-lives of only $\approx 2-4$ days which is $\gg 100$ times faster than in the preceding months. Fast dissipation coincided with high water temperatures and

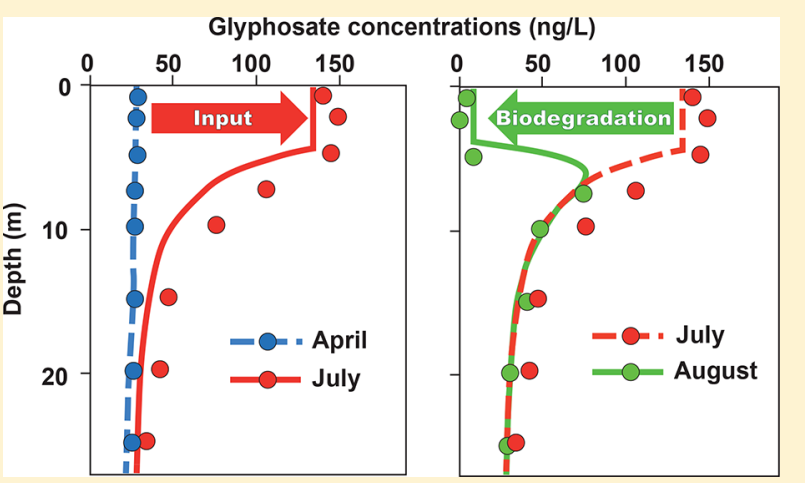
phytoplankton densities, and low phosphate concentrations. This indicates that glyphosate might have been used as an alternative phosphorus source by bacterio- and phytoplankton. Metagenomic analysis of lake water revealed the presence of organisms known to be capable of degrading glyphosate and AMPA.

\section{INTRODUCTION}

Glyphosate is a nonselective, herbicidally active compound with widespread use in agriculture. With an estimated annual use of $8.3 \times 10^{8} \mathrm{~kg}$ active substance in 2014 , it is currently the most important pesticide worldwide. ${ }^{1}$ Nonagricultural applications of glyphosate such as weed control on railroad tracks, along roadways, and in private gardens probably constitute a small portion of the total use, but may contribute substantially to the overall loads in surface waters in densely populated areas. ${ }^{2-5}$

Degradation of glyphosate in soil generally is fast. However, half-lives in different soils vary over a wide range (e.g., 1-67 days in laboratory studies). ${ }^{6}$ Besides the biological activity of the soil, factors affecting the sorption of glyphosate to soil particles such as presence of iron and aluminum oxides (as sorption sites) and phosphate (competing for sorption sites) also seem to have an impact on the rate of degradation. ${ }^{7}$ Two main pathways for biodegradation in soil have been reported, the oxidoreductase pathway leading to the formation of aminomethylphosphonic acid (AMPA) and the C-P lyase pathway leading to the breakage of the $\mathrm{C}-\mathrm{P}$ bond and formation of the amino acid sarcosine (Figure 1). Both metabolites are subsequently further degraded. ${ }^{7,8}$
Despite its relatively rapid degradation in soil and fairly strong sorption to soil particles, glyphosate and AMPA are transported from agricultural fields to surface waters via runoff during rain events. The compounds are thus ubiquitously present in surface waters, frequently in concentrations exceeding $1 \mu \mathrm{g} / \mathrm{L} .^{3,4,9-13}$ However, fairly low concentrations of glyphosate and AMPA of $<1-70 \mathrm{ng} / \mathrm{L}$ were reported in two lakes in the Swiss plateau (Greifensee, Murtensee) in summer 2006, whereas concentrations in the tributaries of both lakes were much higher $(30-390 \mathrm{ng} / \mathrm{L}) .{ }^{11}$ Vertical concentration profiles showed that concentrations near the surface of the lakes were depleted, indicating some removal of glyphosate and AMPA in the epilimnion. ${ }^{11}$

Degradation of glyphosate in natural waters depends on the local conditions. While the compound is stable toward hydrolysis, ${ }^{6}$ indirect photolysis may play a (minor) role in shallow water bodies. ${ }^{6,14-17}$ Rapid dissipation from the water

Received: January 17, 2018

Revised: March 12, 2018

Accepted: March 21, 2018

Published: March 27, 2018 


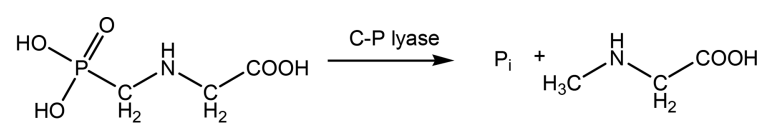

Glyphosate Sarcosine

Glyphosate-

oxidoreductase

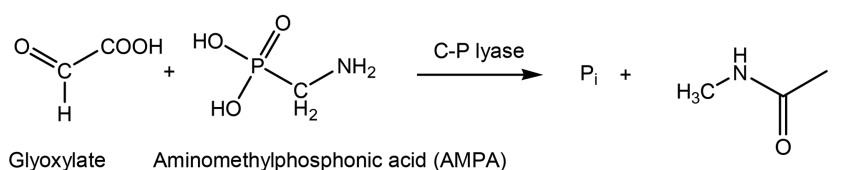

Planine

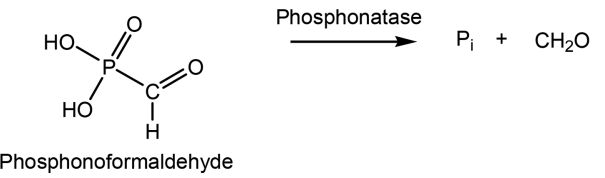

Figure 1. Microbial degradation pathways of glyphosate adapted from refs. ${ }^{8,38}$ According to ref 38 , transformation of AMPA by C-P lyase is preceded by acetylation and hence the product is $\mathrm{N}$-methylacetamide.

phase (time needed for dissipation of $50 \%, \mathrm{DT}_{50}, 1-13$ days) and slow to moderately rapid biodegradation $\left(\mathrm{DT}_{50} 8.5-93\right.$ days) was observed in water/sediment systems. ${ }^{6,18}$ However, the actual degradation seems to occur mainly in the sediment phase. $^{18}$ It may thus be expected that biodegradation in larger water bodies is slower.

The ability of selected bacterial phyla such as cyanobacteria or classes such as betaproteobacteria to degrade phosphonates has been reported. ${ }^{19,20}$ In fact, certain bacteria or bacterial communities can use phosphonates as the sole $\mathrm{P}$ source in the absence of phosphate $\left(\mathrm{P}_{\mathrm{i}}\right) .^{21-23}$ Three different mechanisms and gene networks have been described which enable bacteria to mediate this phosphonate degradation, ${ }^{24,25}$ and other studies have summarized the occurrence of these phosphonate metabolism genes in different bacterial genera, ${ }^{26}$ or focused on the geographical distribution of phosphonate degrading bacteria. $^{27}$ Moreover, phosphonate metabolism has been characterized in a P-starved lake and the analysis of public metagenomics data sets from various freshwater lakes identified homologues of $\mathrm{phnJ}$, whose product is involved in cleavage of the $\mathrm{C}-\mathrm{P}$ bond of phosphonates in more than $75 \%$ of the cases. $^{28}$

In this study, we investigated the origin, distribution, and degradation of glyphosate and its metabolite AMPA in a lake system at multiple levels. We studied the seasonal dynamics of their input, distribution, dissipation, and export in Lake Greifensee during the time when the compound is expected to be applied in the catchment area from early spring to late fall. Concentrations were measured in the main tributaries, in treated wastewater from a large wastewater treatment plant (WWTP) in the catchment area, at several depths in the lake, and at the outflow. Measured concentrations were fed into a lake model and vertical concentration profiles were simulated based on measured input to and export from the lake. Dissipation rate constants necessary to explain the rapid concentration drop in the epilimnion during summer were determined by fitting simulated concentration profiles to measured concentrations in the lake. Furthermore, processes that potentially could lead to dissipation in the lake were evaluated and biodegradation was found to be the most likely cause. We then aimed at identifying the bacterial taxonomic units responsible for the rapid degradation of glyphosate and AMPA in Lake Greifensee through metagenomic sequencing. Finally, we conducted incubation experiments with cyanobacteria to investigate whether it is the presence of these organisms alone or a combination with other factors (i.e., depletion of $\mathrm{P}_{\mathrm{i}}$ ) that result in the sudden disappearance of the compounds.

\section{EXPERIMENTAL SECTION}

Field Site: Greifensee and its Catchment Area. The field study was conducted in the catchment area of Lake Greifensee, a eutrophic lake located near Zurich, Switzerland $\left(47^{\circ} 21^{\prime} \mathrm{N}, 8^{\circ} 41^{\prime} \mathrm{E}\right)$. The lake has a surface area of $8.46 \mathrm{~km}^{2}$ (length: $6.5 \mathrm{~km}$; width: $1.9 \mathrm{~km}$ ), a maximum depth of $32 \mathrm{~m}$, and is dimictic with vertical mixing from surface to bottom in autumn and spring. During the warmer season (AprilNovember) the lake is stratified into a warmer epilimnion and a cold hypolimnion. Regular sequences of oxic (winter/ spring) and anoxic conditions (summer/fall) are observed in the hypolimnion of the lake. It is fed by several tributaries of which the rivers Aa Uster and Aa Mönchaltorf contribute more than $60 \%$ of the total inflow. Its sole outflow is the river Glatt. More details on the hydrology and morphology of the lake are found elsewhere. ${ }^{29}$

Lake Greifensee has a catchment area of $160 \mathrm{~km}^{2}$ of which $\approx 50 \%$ are used as agricultural land (field crops, grassland, and some orchards). Forests (21\%), urban areas (19\%), water bodies $(7 \%)$, and unproductive land $(3 \%)$ constitute the other $50 \%$ of the catchment area. ${ }^{30}$ Approximately 120000 inhabitants are living in the catchment area, most of them in that of Aa Uster, which is more urbanized than the Aa Mönchaltorf. Eight WWTPs are located in the catchment area, of which two discharge directly into the lake and one into Aa Mönchaltorf downstream of the gauging and sampling station. A map of the catchment with the sampling locations can be found in the Supporting Information (SI), Figure S1.

Water Sampling and Analysis. To establish a mass balance for glyphosate and its metabolite AMPA in the lake, monthly water samples were taken from 10 different depths $(0$, $1,2.5,5,7.5,10,15,20,25$, and $30 \mathrm{~m}$ ) between March and November 2013 by regional authorities (Canton of Zurich), who also measured orthophosphate concentrations. During the same period, weekly flow-proportional composite samples of the rivers Aa Mönchaltorf, Aa Uster, and Glatt were analyzed, allowing determination of input and export loads of the two compounds, based on concentration measurements and river water discharge data (for more detail, see the SI). In rare cases (five incidents), when the automated sampling of the tributaries malfunctioned, concentrations were interpolated from values of adjacent weeks.

In WWTP Uster, the largest WWTP in the study area, flowproportional, $24 \mathrm{~h}$ composite samples of treated wastewater were taken every 4-16 days (on average every 8.5 days). The installation operates with a mechanical, biological (activated sludge with an estimated sludge age of 17-20 days, with nitrification and denitrification), and chemical treatment (phosphate precipitation by iron salts, no chlorination), and subsequent sand filtration.

Details of the analytical method are given elsewhere. ${ }^{13}$ In summary: all samples were transferred to the lab in HDPE 
bottles, fortified with an internal standard solution $\left({ }^{13} \mathrm{C}_{2}{ }^{15} \mathrm{~N}\right.$ glyphosate and ${ }^{13} \mathrm{C}^{15} \mathrm{ND}_{2}$-AMPA), and kept at $4{ }^{\circ} \mathrm{C}$ until analysis, typically within 1 week of arrival. Samples were analyzed with a method based on derivatization with fluorenylmethyloxycarbonyl chloride (FMOC-Cl), online-enrichment, reversed-phase liquid chromatography, and tandem mass spectrometry. This method does not include a filtration step so that measured concentrations comprise dissolved and sorbed glyphosate and AMPA. Limits of quantification were 5 ng/L for both compounds. ${ }^{13}$

Lake Model. The software AQUASIM (Version $2.1 \mathrm{~g}$, available from http://www.eawag.ch/en/department/siam/ software/) was used to establish a mathematical model for simulation of vertical concentration profiles and mass balances for glyphosate and AMPA in Lake Greifensee with a temporal resolution of 1 day. ${ }^{31}$ This model was used before in a comparable study on the fate of the herbicide metolachlor. ${ }^{32}$ It considers the morphology and hydrology of the lake as well as fate and vertical transport of chemical compounds. The lake is described by 128 horizontal boxes of $25 \mathrm{~cm}$ thickness, for which horizontal mixing within 1 day is assumed. Vertical mixing is described by time- and depth-dependent diffusion coefficients derived from fitting water temperatures to measured vertical temperature profiles.

A water balance was set up with discharge data from gauging stations of the three largest tributaries and the outflow of the lake, lake water levels, evaporation, and precipitation data. The discharge of the remaining nine minor tributaries was calculated by the difference of the above-mentioned. Subsurface water exchange can be neglected $(<5 \%)$.

Chemical input of glyphosate and AMPA into the lake was modeled to occur exclusively through the tributaries into the epilimnion of the lake. For the unknown inputs from those tributaries that were not sampled, average concentrations of Aa Mönchaltorf and Aa Uster were used and multiplied with the estimated discharge (see above). Input through the three WWTPs was calculated from the sum of their discharge and the concentrations found in WWTP Uster, which accounts for $>85 \%$ of the treated wastewater directly entering the lake.

The model comprises a degradation process in the lake's epilimnion which was implemented as a (pseudo) first-order degradation in the upper $0.5 \mathrm{~m}$ layer of the lake. Through the fast vertical diffusion within the epilimnion, this degradation process affects the concentrations in the whole epilimnion. The degradation rates reported in the Results and Discussion section were thus recalculated using the actual depth of the epilimnion (based on temperature profiles) to refer to the whole epilimnion.

Metagenomic Sequencing. Lake Greifensee water was sampled at three depths $(0,2.5$, and $7.5 \mathrm{~m})$ on July 7,2014 . 1L of lake water per sample was then centrifuged at $5000 \mathrm{rcf}$ for 10 min and the pellet was stored at $-20{ }^{\circ} \mathrm{C}$ until further processing. Total DNA was extracted using the PowerSoil DNA isolation kit (MO BIO, Carlsbad, CA). The integrity of the DNA was assessed on agarose gels and the quantity was measured by the Quant-iT PicoGreen kit (Invitrogen, Carlsbad, CA). Libraries were generated and indexed using the TruSeq DNA library preparation kit (Illumina, San Diego, CA) and sequenced on an Illumina MiSeq generating $300 \mathrm{bp}$ paired end reads available under (https://www.mg-rast.org/linkin. cgi?project=mgp 1139). All metagenomic data analyses were performed on the MG-RAST server. ${ }^{33}$

\section{RESULTS AND DISCUSSION}

Major Inputs of Glyphosate and AMPA to the Lake from Tributaries and WWTP Uster. Glyphosate concentrations in the weekly composite samples from the two main tributaries ranged from $<5$ to $1430 \mathrm{ng} / \mathrm{L}$ (median, $145 \mathrm{ng} / \mathrm{L}$ in Aa Mönchaltorf and $175 \mathrm{ng} / \mathrm{L}$ in Aa Uster; SI Table S3). The highest concentrations appeared in July and August in Aa Mönchaltorf and in March and July in Aa Uster, which is consistent with the main agricultural uses of glyphosate for treatment of sugar beet and maize fields prior to seeding in spring and postharvest treatment of cereal fields in summer. Urban use of glyphosate is not so well-defined, but is expected to have a higher impact on the concentrations in Aa Uster, which has a higher percentage of urban land use. ${ }^{3,13}$ Glyphosate concentrations in treated wastewater from WWTP Uster were between 18 and $350 \mathrm{ng} / \mathrm{L}$ (median, $106 \mathrm{ng} / \mathrm{L}$; SI Table S4) with maximum concentrations in June and September, when they exceeded those in the tributaries.

AMPA concentrations in the two main tributaries ranged from 24 to $415 \mathrm{ng} / \mathrm{L}$ (median, $150 \mathrm{ng} / \mathrm{L}$ in both rivers; SI Table S3). Similar to glyphosate, the highest AMPA concentrations were found in July (Aa Uster) and August (Aa Mönchaltorf). Concentrations in treated wastewater from WWTP Uster reached up to $1680 \mathrm{ng} / \mathrm{L}$ (median, $516 \mathrm{ng} / \mathrm{L}$; SI Table S4), and were thus higher than those in the tributaries at all sampling times. Maximum concentrations in wastewater were found in August and September. AMPA is also a degradation product of various phosphonates used in industry ${ }^{34}$ and degradation of these compounds to AMPA in WWTPs likely is an important source of AMPA in Lake Greifensee.

Spearman's rank correlation analysis indicated fairly strong correlation of glyphosate and AMPA concentrations in the more rural tributary Aa Mönchaltorf $(\sigma=0.70, p<0.001)$ suggesting that the occurrence of AMPA in this stream probably was related to the use of glyphosate in the catchment area. In contrast, in the more urban tributary Aa Uster, there was no apparent correlation $(\sigma=0.31, p=0.09)$ indicating that AMPA may, at least in part, be derived from sources other than glyphosate in the catchment. Even in treated wastewater from WWTP Uster, the correlation between glyphosate and AMPA was higher $(\sigma=0.62, p<0.001)$ than in Aa Uster. The best correlation, however, was found in the outflow of the lake ( $\sigma=$ $0.83, p<0.001)$. This is most likely due to the similar fate of the two compounds (see below) rather than similar sources.

Weekly loads of glyphosate into Lake Greifensee (Figure 2b) were up to 0.97 and $0.63 \mathrm{~kg}$ in Aa Mönchaltorf and Aa Uster, respectively. Inputs from the more urbanized catchment area of Aa Uster were highest and quite uniform between March and June. From July on, these inputs decreased to lower levels. Inputs from the agriculturally dominated catchment area of Aa Mönchaltorf started later (mid-April) and fluctuated with a clear maximum during the rainiest week at the end of May. Glyphosate loads from WWTP Uster were generally low and lower than those in the tributaries at all times. Highest loads from WWTPs were found in June.

Weekly loads of AMPA into Lake Greifensee (Figure 2c) reached their maximum in the week with the highest precipitation, with values of 0.64 and $0.57 \mathrm{~kg}$ for Aa Mönchaltorf and Aa Uster, respectively. In other weeks, AMPA loads were generally below $0.3 \mathrm{~kg}$. Median AMPA loads from treated wastewater of WWTP Uster were $0.08 \mathrm{~kg}$ week $^{-1}$ with a maximum of $0.14 \mathrm{~kg}$ in September. Compared 

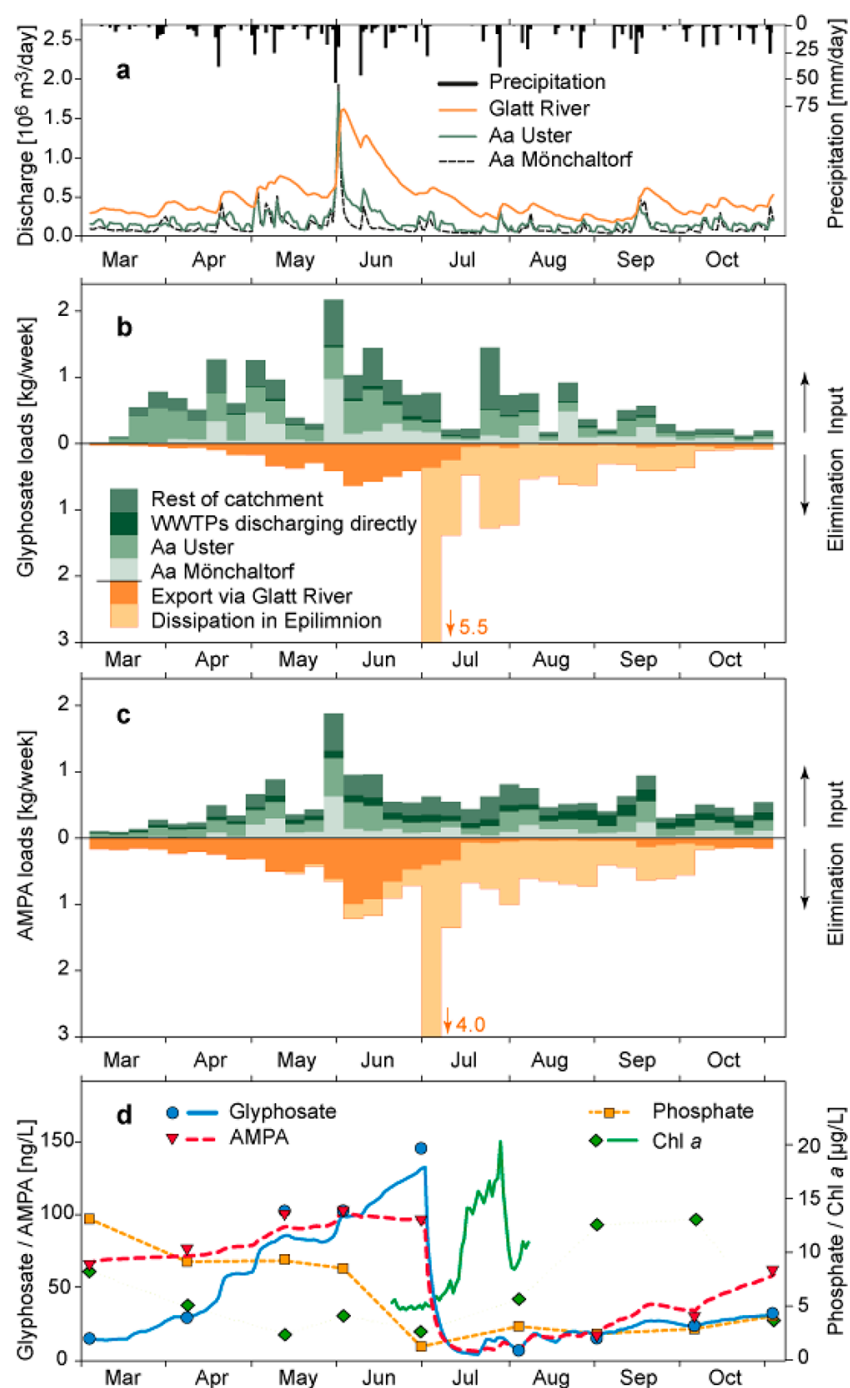

Figure 2. Daily precipitation in 2013 at a nearby weather station and water discharges at the outflow of Lake Greifensee (Glatt River) and the two main tributaries, Aa Uster and Aa Mönchaltorf (a). Mass loads of glyphosate (b) and AMPA (c) which were transported to and eliminated from the lake, respectively. Concentrations of glyphosate and AMPA (symbols indicate measured values, lines modeled concentrations) as well as phosphate in the uppermost $5 \mathrm{~m}$ of Lake Greifensee (d). Chl a was measured either monthly at a depth of $1 \mathrm{~m}$ (symbols) or in situ over a depth of $1.5-16 \mathrm{~m}$ (the line indicates mean values from 1.5 to $8 \mathrm{~m}$, data from ref 41 ).

with glyphosate, wastewater delivered significant amounts of AMPA, which regularly reached levels similar to those in one of the tributaries and even exceeded the loads in both main tributaries in the first week of September.

Concentrations of Glyphosate and AMPA in Lake Greifensee: Rapid Dissipation in the Epilimnion During Summer. Vertical concentration profiles of glyphosate and AMPA in Lake Greifensee were measured monthly between March and November 2013 (SI Table S1). Selected profiles are shown in Figure 3 (see all profiles in SI Figure S2 and S3). In March and April, glyphosate concentrations were uniform at all depths except for the lowermost sample, which showed lower glyphosate concentrations. Concentrations (slowly) increased from $\approx 14 \mathrm{ng} / \mathrm{L}$ in March to $28 \mathrm{ng} / \mathrm{L}$ in April.

Between April and May, rising surface water temperatures initiated the stratification of the lake with the formation of an

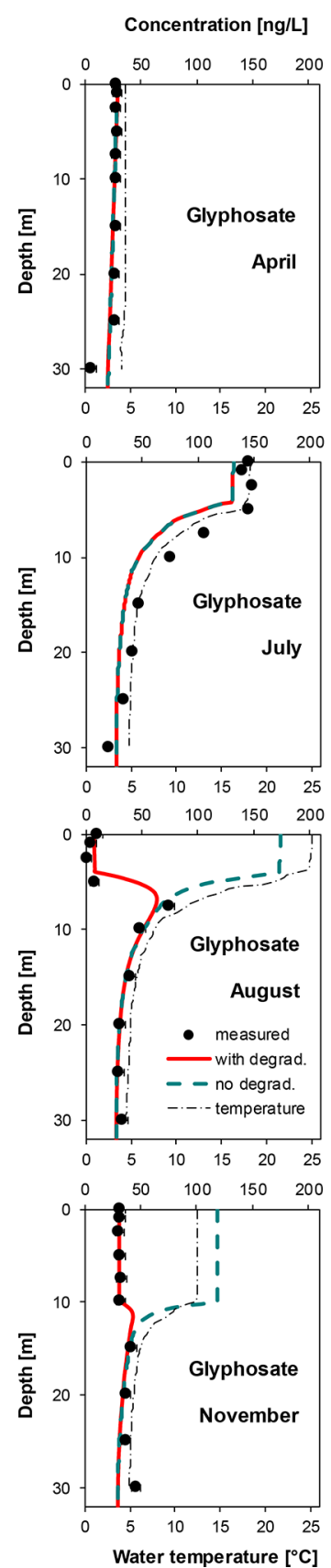

Concentration [ng/L]
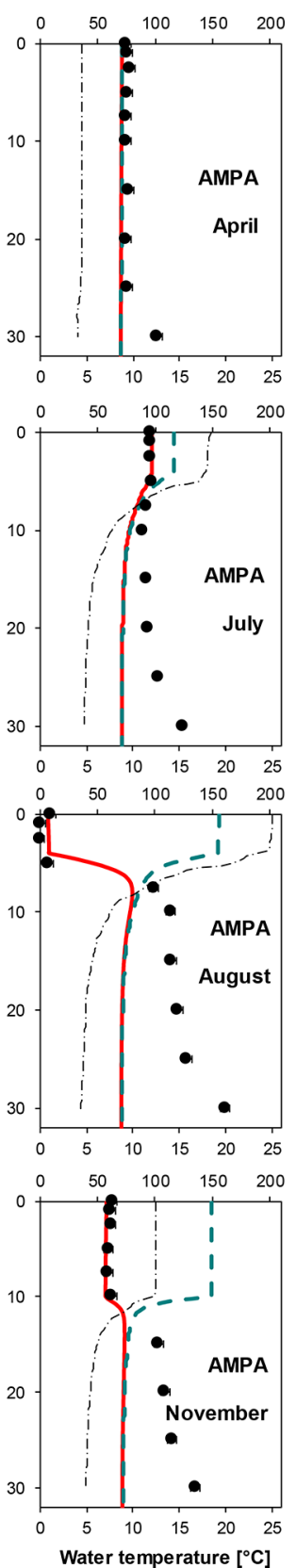

Figure 3. Selected vertical concentration profiles of glyphosate (left) and AMPA (right) in Lake Greifensee, 2013 (see SI Figures S2 and S3 for a complete set of profiles). Measured values (circles) are compared to simulated concentrations assuming no degradation (blue dashed lines) or degradation in the epilimnion (red line). Also shown are the measured temperature profiles (dash dotted black lines).

epilimnion in the upper 4-6 $\mathrm{m}$ and a hypolimnion in the lowest $20 \mathrm{~m}$. Both are divided by the metalimnion with a pronounced temperature (and thus density) gradient, which restricts water exchange between the epi- and the hypolimnion. Hence, beginning in May, glyphosate epilimnion concentrations increased steadily to values higher than $100 \mathrm{ng} / \mathrm{L}$ due to inputs from the tributaries, whereas hypolimnion concentrations remained constant $(\approx 35 \mathrm{ng} / \mathrm{L})$.

In July, epilimnion concentrations of glyphosate reached a maximum of $145 \mathrm{ng} / \mathrm{L}$ (Figure 3). However, between July and August, a sudden drop of glyphosate concentrations occurred in 
the epilimnion down to levels below the limit of quantification of $5 \mathrm{ng} / \mathrm{L}$, despite further inputs through the tributaries. This is also illustrated in Figure $2 \mathrm{~d}$, where average epilimnion concentrations are plotted over time. These observations indicate a sudden, rapid dissipation in the epilimnion, which will be discussed in detail below.

From September onward, glyphosate concentrations again slowly increased due to further inputs, but also due to the fact that the depth of the epilimnion was increasing, causing mixing with water from deeper layers containing higher concentrations. Eventually epilimnion concentrations reached $30 \mathrm{ng} / \mathrm{L}$ in November (Figure 3).

For AMPA, a similar temporal pattern was observed as for glyphosate. Initial concentrations of AMPA were higher (70 $\mathrm{ng} / \mathrm{L})$ than those of glyphosate $(14 \mathrm{ng} / \mathrm{L})$, but they increased to only $100 \mathrm{ng} / \mathrm{L}$ until July. Between July and August, the same distinct concentration drop was observed in the epilimnion as for glyphosate, suggesting that the same dissipation process acted on both compounds. In the following months, AMPA epilimnion concentrations recovered to preseason levels of about $60 \mathrm{ng} / \mathrm{L}$.

In contrast to glyphosate, AMPA concentrations in the hypolimnion increased, even after the stratification of the lake starting in April, up to concentrations of $130 \mathrm{ng} / \mathrm{L}$ in August (Figure 3). Since the metalimnion prevents water exchange between epilimnion and hypolimnion, this increase cannot originate from input by the tributaries. Furthermore, in all vertical profiles, AMPA concentrations near the bottom $(30 \mathrm{~m}$ depth) were higher than in the rest of the hypolimnion (Figure 3). This coincides with slightly lower glyphosate concentrations between March and July in the same depth as mentioned above. Although further evidence is lacking, one could speculate that AMPA may be formed by degradation of phosphonates present in the hypolimnion and in or near the sediment by degradation of glyphosate and/or other phosphonates. Moreover, in analogy to phosphate, AMPA adsorbed to bottom sediment may be released due to reductive dissolution of iron oxides under anaerobic conditions. However, since the focus of this study was to investigate the fate of glyphosate and AMPA in the epilimnion and given the complexity of the matter (numerous possible AMPA precursors, such as nitrilotris(methylenephosphonic acid) which is used as complexing agent in detergents ${ }^{34}$ ), formation of AMPA in the hypolimnion was not further studied.

In a less extensive study in 2014, the same glyphosate and AMPA concentration trends were found between June and September (SI Table S2).

Mass Balance. Between March and November, the cumulative input loads of both compounds were highest in the more urbanized Aa Uster (7.9 and $6.5 \mathrm{~kg}$ of glyphosate and AMPA, respectively, see Figure $2 b, c)$, followed by the agricultural Aa Mönchaltorf (5.5 and $4.2 \mathrm{~kg}$ ) and WWTP Uster $(0.65$ and $2.7 \mathrm{~kg})$. Further input loads from two other WWTPs $(0.13$ and $0.5 \mathrm{~kg}$ ) were calculated from the sum of their wastewater discharge and the concentrations found in WWTP Uster. Loads from the tributaries not included in the sampling (7.8 and $5.7 \mathrm{~kg}$ ) were calculated based on average concentrations of Aa Mönchaltorf and Aa Uster and the estimated discharge from the water balance.

Cumulative glyphosate input loads of about $22 \mathrm{~kg}$ were in stark contrast to an export via the Glatt river of only $5.4 \mathrm{~kg}$. In November, about $5.1 \mathrm{~kg}$ glyphosate were stored in the lake which was $\approx 3 \mathrm{~kg}$ more than in March $(2.1 \mathrm{~kg})$. This results in a dissipated load of $13.6 \mathrm{~kg}$, which was accounted for in the model by the first-order degradation process with the dissipation rates discussed in the next section. Roughly 70\% of the dissipated load $(9.5 \mathrm{~kg})$ was disappearing within the 5 weeks between the measurements in July and August.

For AMPA, cumulative input loads of $19.6 \mathrm{~kg}$ were similarly contrasted by a relatively low export load of $8.7 \mathrm{~kg}$. Measured storage of AMPA increased from $10.6 \mathrm{~kg}$ in March to $12.1 \mathrm{~kg}$ in November. However, this increase is largely due to formation of AMPA in the hypolimnion. According to the model calculations (see below), $55 \%$ of the $\approx 11 \mathrm{~kg}$ AMPA which disappeared during the study period were eliminated between the measurements in July and August alone.

Application of the Lake Model: Indication for a Rapid Dissipation Process with a Half-Life of a Few Days. To describe the variation of concentrations over time and depth in the lake, a simple, one-dimensional model was set up including inputs from the various tributaries and WWTPs, export via the Glatt River, and vertical mixing, but, in a first step, excluding any degradation/dissipation processes. This model was able to describe the measured, vertical concentration profiles from March to July (dashed blue lines in Figure 3 and SI Figures S2 and S3). However, in August, modeled concentrations in the epilimnion would have reached levels of $200 \mathrm{ng} / \mathrm{L}$ for glyphosate and $160 \mathrm{ng} / \mathrm{L}$ for AMPA. Consequently, all measured epilimnion concentrations after August were considerably overestimated by the model.

To account for the rapid elimination of glyphosate and AMPA, the model was refined by inclusion of a first-order dissipation process in the epilimnion (for details see methods section). Average dissipation rates were adjusted for every period between two lake samplings (21-35 days) until measured epilimnion concentrations were adequately represented by the model. Resulting concentration profiles are shown in Figure 3 and SI Figures S2 and S3 (solid red lines).

For glyphosate, this dissipation process was negligible before July with first-order degradation rates $<0.001 \mathrm{~d}^{-1}$, corresponding to half-lives $\left(\mathrm{DT}_{50}\right)>1000$ days. In July and the first week of August, a considerably higher $(\gg 100 \mathrm{x})$ dissipation rate of $0.38 \mathrm{~d}^{-1}\left(\mathrm{DT}_{50}=1.8\right.$ days $)$ was determined. Dissipation rates between the samplings in August and September remained high $\left(0.19 \mathrm{~d}^{-1} ; \mathrm{DT}_{50}=3.7\right.$ days $)$ and decreased steadily from September $\left(0.05 \mathrm{~d}^{-1} ; \mathrm{DT}_{50}=13\right.$ days $)$ until October $(0.002$ $\mathrm{d}^{-1} ; \mathrm{DT}_{50}>300$ days $)$.

Modeled dissipation rates for AMPA showed the same seasonal trend as those for glyphosate. As for glyphosate, the highest dissipation rate for AMPA was found in July and the first week of August. In general, dissipation rates were very similar to those of glyphosate (SI Table S5).

Evaluation of Possible Elimination Processes for Glyphosate and AMPA in the Lake. The modeled dissipation rates represent all processes that may affect glyphosate and AMPA concentrations in the lake's epilimnion, including potential distribution processes between water and air or water and particles/sediment as well as different degradation processes such as hydrolysis, photodegradation, or biological degradation. The importance of these processes will be assessed in the following paragraphs.

Due to their zwitterionic speciation in lake water, glyphosate and AMPA have a very low vapor pressure and a high water solubility and, consequently, low air-water partition coefficients. ${ }^{6}$ Therefore, volatilization from the water surface can be ruled out as significant loss process. 
Sorption to particles with subsequent sedimentation may lead to a certain loss of glyphosate and AMPA from the epilimnion. However, since the sedimentation of particles is a rather constant process and the sorption to these particles does not change rapidly, this process is unlikely to explain the observed, rapid loss of glyphosate and AMPA from the epilimnion in such a short period. Nonetheless, an estimation of the potential contribution of sorption/sedimentation was done based on a field study at Lake Greifensee with two strongly sorbing xenobiotic compounds. ${ }^{35}$ In that study, concentrations were measured in trapped settling particles as well as in the water column and sorption $K_{\mathrm{d}}$ values were determined (monthly during one year) in the range of 1600$32000 \mathrm{~L} / \mathrm{kg}$. These values were implemented in a onedimensional lake model together with other elimination pathways. Sorption/sedimentation was found to be a relevant elimination process for the two studied compounds with estimated elimination rates in the range of $0.0007-0.005 \mathrm{~d}^{-1} .35$

For glyphosate, median and maximum Freundlich adsorption coefficients $\left(K_{\mathrm{F}}\right)$ measured in soil of 72 and $700 \mathrm{~L} / \mathrm{kg}$, respectively, are reported. ${ }^{6}$ For AMPA, the reported median and maximum sorption $K_{\mathrm{F}}$ values in soil are somewhat higher (77 and $1570 \mathrm{~L} / \mathrm{kg}$, respectively). ${ }^{6}$ Of course, sorption to settling particles in the lake may be different from soil. For example, Maqueda et al. determined $K_{\mathrm{d}}$ values in two sediment samples from a reservoir in the range of 4800 to $11800 \mathrm{~L} / \mathrm{kg}^{36}$ These sediments were rich in iron oxides and clay minerals. Even these higher sorption $K_{d}$ values, however, are below those reported for the target compounds in the study by Stoll et al. ${ }^{35}$ Considering the associated elimination rates stated above, sorption/sedimentation may contribute to some extent to the overall elimination of glyphosate and AMPA, but most certainly cannot explain the rapid elimination in summer.

Both compounds are known to be hydrolytically stable, ${ }^{6}$ which excludes abiotic hydrolysis as elimination process.

Direct or indirect photolysis may also serve as a possible explanation for rapid degradation in the epilimnion. Even though glyphosate and AMPA do not contain a chromophore and thus do not absorb light at wavelengths $>290 \mathrm{~nm}$, there is evidence for slow indirect photolysis ${ }^{6}$ that may be enhanced in the presence of metal ions such as $\mathrm{Fe}$ (III) and other constituents of natural waters. ${ }^{14-17}$ However, a simple photolysis experiment with unfiltered water from Lake Greifensee (sampled on July 26, 2013 at the outlet of the lake; data not shown) showed no significant degradation of glyphosate and AMPA during $7 \mathrm{~h}$ of sunlight exposure (starting concentrations, $100 \mathrm{ng} / \mathrm{L}, 10 \mathrm{~cm}$ water layer) on a cloudless summer day (10 am to 5 pm, July 26, 2013) in Wädenswil, Switzerland (coordinates, $47^{\circ} 13^{\prime} \mathrm{N} 8^{\circ} 40^{\prime} \mathrm{E}$ ). From experience with other compounds in Lake Greifensee, ${ }^{37}$ experimental photolysis half-lives in summer sunlight of $\leq 1 \mathrm{~h}$ would be necessary to have a substantial impact on the concentrations in the epilimnion. Photolysis is thus not expected to contribute significantly to the observed, rapid removal of glyphosate and AMPA in the epilimnion.

This suggests that biodegradation is the most likely main elimination process to reasonably explain the distinct concentration drop of glyphosate and AMPA in Lake Greifensee between July and August. This conclusion is supported by the finding that phytoplankton growth was higher in July and the following months (with a short peak between the samplings in July and August; green line in Figure $2 \mathrm{~d}$ ) and that water temperatures were higher at the same time.
Nevertheless, increasing phytoplankton density and water temperature alone would be expected to promote biodegradation, but still seem unlikely to be the sole cause of the sudden concentration drop, unless the conditions led to rapid growth of organisms, capable of degrading glyphosate and AMPA.

An additional factor enhancing biodegradation of glyphosate and AMPA may be the decreasing free phosphate (orthophosphate) concentration in the epilimnion, which fell below the limit of detection of $2 \mu \mathrm{g} \mathrm{P} / \mathrm{L}$ in July (Figure $2 \mathrm{~d}$ ). As known from the literature (ref 38 and references cited therein), several bacteria, such as cyanobacteria or proteobacteria, are able to take up phosphonates and break the relatively stable $\mathrm{C}-\mathrm{P}$ bond. This degradation process is especially effective under phosphate depleted conditions. While transcription of the phosphonate uptake gene $p h n D$ was shown to be constitutively active, ${ }^{39}$ transcript levels of the phosphonate degrading gene phnJ were higher in P-starved conditions. ${ }^{28}$ Similar P-starved conditions were found in Lake Greifensee in July and August. In this case, the bacteria could use the phosphonates as alternative $\mathrm{P}$ sources, which gives them a competitive advantage. ${ }^{7,24,40}$ Breakdown products are the amino acid sarcosine and methylacetamide from degradation of glyphosate and AMPA, respectively, which are further mineralized (Figure 1).

The degradation of glyphosate and AMPA by cyano- and/or proteobacteria is also supported by the observation that measured concentrations in August were lowest in the depths 1 and $2.5 \mathrm{~m}$, where they fell below the limit of quantification of $5 \mathrm{ng} / \mathrm{L}$, whereas in the depths 0 and $5 \mathrm{~m}$, concentrations were between 8 and $11 \mathrm{ng} / \mathrm{L}$ despite the rather rapid mixing in the epilimnion. This suggests that degradation took place in a zone below the water surface around $1-2.5 \mathrm{~m}$ depth, which was also the zone of maximum primary production. ${ }^{41}$

Metagenomic Sequencing to Identify Organisms Responsible for the Rapid Degradation of Glyphosate. In July 2014, shortly after full depletion of glyphosate and AMPA, water samples for metagenomic analysis were taken from the epilimnion of Lake Greifensee. Sequencing yielded a total of $8.8 \mathrm{Gbp}$ of sequence information. From these data, species abundance was estimated at multiple taxonomic levels (see SI for details). The most abundant phyla were cyanobacteria and proteobacteria. At the genus level, Synechococcus showed the highest abundance (SI Figure S5).

In order to further evaluate possible routes of phosphonate degradation in Lake Greifensee, the abundance of genes linked to phosphonate degradation (ref 38 and references cited therein) and their respective species of origin was evaluated using MG-RAST. ${ }^{33}$ The phnCDE genes previously linked to phosphonate uptake were highly abundant in the sample and were assigned mainly to the genus Synechococcus (Chroococcales, Figure 4). Relatively few DNA reads mapped to selected $\mathrm{C}-\mathrm{P}$ lyase pathway genes ( $p h n K L N$, Figure 4 ) and thus some evidence for a working $\mathrm{C}-\mathrm{P}$ lyase pathway was found. These genes were assigned to proteobacteria (Burkholderiales and Enterobacteriales), as were the genes phnWX of the phosphonatase pathway (Figure 1). The gene thiO, previously reported to catalyze the oxidation reaction from glyphosate to AMPA, was associated with the families of Chroococcales, Burkholderiales and Prochlorales (Figure 4). No evidence of a glyphosate oxidoreductase gene ( $g \circ x)$, previously linked to microbial glyphosate oxidation, ${ }^{42}$ was found within this study. All these data indicate that microorganisms of multiple genera 


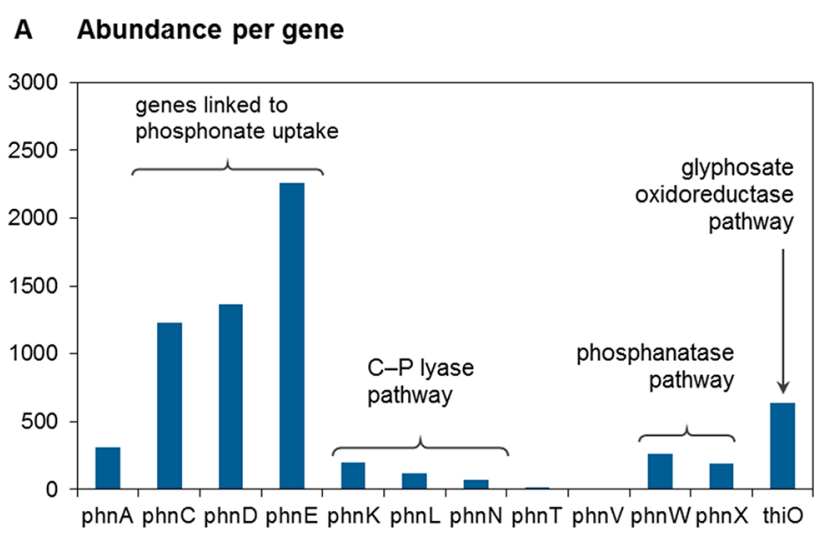

B Origin of selected genes

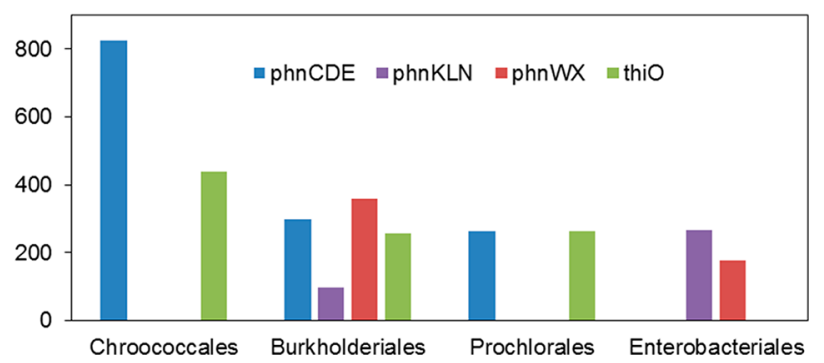

Figure 4. Functional abundance of selected genes in the Lake Greifensee metagenome (A) and assignment of some of these genes to families of bacteria (B).

may be involved in the biodegradation of glyphosate and that the compound is probably degraded via different pathways.

Evidence for Biodegradation from Batch Incubation Experiments. Batch incubation experiments were performed with two cyanobacterial species, Microcystis aeruginosa (isolated from Lake Greifensee) and Synechococcus (isolated from another Swiss lake). The experiments and results are described in detail in the SI. In summary, the experiments with Microcystis aeruginosa and Synechococcus showed that glyphosate is rapidly degraded and that degradation depends on the depletion of phosphate in the growth medium (no degradation or much slower degradation in the presence of $\mathrm{P}_{\mathrm{i}}$ ). Extrapolated to a biomass corresponding to $15 \mu \mathrm{g} / \mathrm{L}$ chlorophyll $a$, as measured in summer 2013 in Lake Greifensee ${ }^{41}$ (Figure 2d), the dissipation rates for $\mathrm{P}_{\mathrm{i}}$-starved Microcystis aeruginosa (0.07 $\left.\mathrm{d}^{-1}\right)$ and Synechococcus $\left(0.18 \mathrm{~d}^{-1}\right)$ were, however, somewhat lower than the rate obtained through modeling, indicating that microorganisms capable of degrading glyphosate and AMPA more efficiently than the two tested species must be present in the lake's epilimnion.

Environmental Implications. From the available data, dissipation of glyphosate and AMPA in large water bodies (i.e., lakes), where transfer to and degradation in sediment is less important, is expected to be fairly slow. ${ }^{6,18}$ However, our study shows that under certain conditions, degradation of both compounds is orders of magnitude faster than expected. The conditions leading to this phenomenon do not seem to be very specific as they were met in Lake Greifensee at least in the summers of 2006, ${ }^{11}$ 2013, and 2014 and in lake Murten in $2006{ }^{11}$ Note that in 2006, only a single vertical concentration profile was measured in the two lakes in summer. Nevertheless, as the use pattern was very similar at the time (at least concerning application timing and consequent input to surface waters via surface runoff) it appears likely that the same seasonal changes caused the observed depletion of glyphosate and AMPA in the epilimnion.

A likely explanation for the rapid degradation is a combination of the bloom of cyanobacteria during summer and a depletion of inorganic phosphorus that probably caused increased uptake and metabolism of phosphonates in these organisms. The distinct seasonal dynamics as well as the specific conditions required for efficient degradation of glyphosate and AMPA probably are difficult to reproduce in laboratory degradation experiments as requested in official guidelines for pesticide testing such as the OECD tests for transformation in aquatic sediment systems ${ }^{43}$ or aerobic mineralization in surface water. ${ }^{44}$ However, our study provides strong evidence, at field scale, for the potential of (cyano)bacteria in lakes for degradation of glyphosate and AMPA. Moreover, this may also apply to other organic phosphonates. As organic phosphonates are increasingly used in household detergents and many industrial processes and thus end up in wastewater and in the aquatic environment, ${ }^{34,45}$ natural attenuation processes and maybe even options for their bioremediation will become increasingly relevant in the future. Given the results of our study, it would be worthwhile to conduct a similar study with other organic phosphonates which are used in large enough quantities to become relevant environmental contaminants.

\section{ASSOCIATED CONTENT}

\section{S Supporting Information}

The Supporting Information is available free of charge on the ACS Publications website at DOI: 10.1021/acs.est.8b00314.

Information on the catchment area of Lake Greifensee including sampling points, additional details to the Experimental Section, the incubation experiments with cyanobacterial cultures, the metagenomics sequencing, and detailed analytical results including Tables S1-S5 and Figures S1-S7 (PDF)

\section{AUTHOR INFORMATION}

\section{Corresponding Author}

*Phone: +41 5846062 89; fax: +41 5846063 41; e-mail: thomas.poiger@agroscope.admin.ch.

ORCID $\odot$

Juliane Hollender: 0000-0002-4660-274X

Thomas Poiger: 0000-0003-4205-4261

Notes

The authors declare no competing financial interest.

\section{ACKNOWLEDGMENTS}

We thank Astrid Bächli, Martina Keller, Markus Oggenfuss, and Sahitya Sivagulanathan for their support in the laboratory, Alexander Öhler, Karin Rykart, Markus Blum, and Thomas Reimann from AWEL for sampling on lake Greifensee, Eugen Weder from the WWTP Uster for his support and access to WWTP effluent samples, and Labor Veritas, Zurich for sample collection at the tributaries and the effluent of the lake. We also thank Esther Kohler and Jonathan Muri for valuable discussions and literature review of potential biochemical degradation pathways. Finally, we thank the reviewers for their valuable comments during the review process. Funding for this research was provided by the Office for Waste, Water, Energy, and Air of the Canton of Zurich (AWEL), Switzerland, and we thank Pius 
Niederhauser for his support. Further support came from the Swiss National Science Foundation grants 315230_141190 and 205320_165935.

\section{REFERENCES}

(1) Benbrook, C. M. Trends in glyphosate herbicide use in the United States and globally. Environ. Sci. Eur. 2016, 28 (1), 1-15.

(2) Botta, F.; Lavison, G.; Couturier, G.; Alliot, F.; Moreau-Guigon, E.; Fauchon, N.; Guery, B.; Chevreuil, M.; Blanchoud, H. Transfer of glyphosate and its degradate AMPA to surface waters through urban sewerage systems. Chemosphere 2009, 77 (1), 133-139.

(3) Hanke, I.; Wittmer, I.; Bischofberger, S.; Stamm, C.; Singer, H. Relevance of urban glyphosate use for surface water quality. Chemosphere 2010, 81 (3), 422-429.

(4) Kolpin, D. W.; Thurman, E. M.; Lee, E. A.; Meyer, M. T.; Furlong, E. T.; Glassmeyer, S. T. Urban contributions of glyphosate and its degradate AMPA to streams in the United States. Sci. Total Environ. 2006, 354 (2-3), 191-197.

(5) Skark, C.; Zullei-Seibert, N.; Willme, U.; Gatzemann, U.; Schlett, C. Contribution of non-agricultural pesticides to pesticide load in surface water. Pest Manage. Sci. 2004, 60 (6), 525-530.

(6) European Food Safety Authority (EFSA). Conclusion on the peer review of the pesticide risk assessment of the active substance glyphosate. EFSA J. 2015, 13 (11), 4302.

(7) Borggaard, O. K.; Gimsing, A. L. Fate of glyphosate in soil and the possibility of leaching to ground and surface waters: A review. Pest Manage. Sci. 2008, 64 (4), 441-456.

(8) Sviridov, A. V.; Shushkova, T. V.; Ermakova, I. T.; Ivanova, E. V.; Epiktetov, D. O.; Leontievsky, A. A. Microbial degradation of glyphosate herbicides (review). Appl. Biochem. Microbiol. 2015, 51 (2), 188-195.

(9) Battaglin, W. A.; Meyer, M. T.; Kuivila, K. M.; Dietze, J. E. Glyphosate and Its Degradation Product AMPA Occur Frequently and Widely in U.S. Soils, Surface Water, Groundwater, and Precipitation. J. Am. Water Resour. Assoc. 2014, 50 (2), 275-290.

(10) Coupe, R. H.; Kalkhoff, S. J.; Capel, P. D.; Gregoire, C. Fate and transport of glyphosate and aminomethylphosphonic acid in surface waters of agricultural basins. Pest Manage. Sci. 2012, 68 (1), 16-30.

(11) Hanke, I.; Singer, H.; Hollender, J. Ultratrace-level determination of glyphosate, aminomethylphosphonic acid and glufosinate in natural waters by solid-phase extraction followed by liquid chromatography-tandem mass spectrometry: performance tuning of derivatization, enrichment and detection. Anal. Bioanal. Chem. 2008, 391 (6), 2265-76.

(12) Horth, H.; Blackmore, K. Survey of Glyphosate and AMPA in Groundwaters and Surface Waters in Europe; UC8073.02/15276-0; WRc Swindon, 2009.

(13) Poiger, T.; Buerge, I. J.; Bächli, A.; Müller, M. D.; Balmer, M. E. Occurrence of the herbicide glyphosate and its metabolite AMPA in surface waters in Switzerland determined with online solid phase extraction LC-MS/MS. Environ. Sci. Pollut. Res. 2017, 24, 1588.

(14) Chen, Y.; Wu, F.; Zhang, X.; Deng, N. S.; Bazhin, N.; Glebov, E. $\mathrm{Fe}(\mathrm{III})$-pyruvate and $\mathrm{Fe}(\mathrm{III})$-citrate induced photodegradation of glyphosate in aqueous solutions. J. Coord. Chem. 2007, 60 (22-24), 2431-2439.

(15) Haag, W. R; Yao, C. C. D. Rate Constants for Reaction of Hydroxyl Radicals with Several Drinking-Water Contaminants. Environ. Sci. Technol. 1992, 26 (5), 1005-1013.

(16) Lundhoie, K.; Friestad, H. O. Photodegradation of the Herbicide Glyphosate in Water. Bull. Environ. Contam. Toxicol. 1986, 36 (5), 723-729.

(17) Mallat, E.; Barcelo, D. Analysis and degradation study of glyphosate and of aminomethylphosphonic acid in natural waters by means of polymeric and ion-exchange solid-phase extraction columns followed by ion chromatography post-column derivatization with fluorescence detection. J. Chromatogr. A 1998, 823 (1-2), 129-136.

(18) Wang, S.; Seiwert, B.; Kästner, M.; Miltner, A.; Schäffer, A.; Reemtsma, T.; Yang, Q.; Nowak, K. M. (Bio)degradation of glyphosate in water-sediment microcosms - A stable isotope colabeling approach. Water Res. 2016, 99, 91-100.

(19) Quinn, J. P.; Kulakova, A. N.; Cooley, N. A.; McGrath, J. W. New ways to break an old bond: the bacterial carbon-phosphorus hydrolases and their role in biogeochemical phosphorus cycling. Environ. Microbiol. 2007, 9 (10), 2392-2400.

(20) White, A. K.; Metcalf, W. W., Microbial metabolism of reduced phosphorus compounds. In Annu. Rev. Microbiol., 2007; Vol. 61, pp 379-400. DOI: 10.1146/annurev.micro.61.080706.093357.

(21) Forlani, G.; Mangiagalli, A.; Nielsen, E.; Suardi, C. M. Degradation of the phosphonate herbicide glyphosate in soil: Evidence for a possible involvement of unculturable microorganisms. Soil Biol. Biochem. 1999, 31 (7), 991-997.

(22) Forlani, G.; Pavan, M.; Gramek, M.; Kafarski, P.; Lipok, J. Biochemical bases for a widespread tolerance of cyanobacteria to the phosphonate herbicide glyphosate. Plant Cell Physiol. 2008, 49 (3), $443-56$.

(23) Saxton, M. A.; Morrow, E. A.; Bourbonniere, R. A.; Wilhelm, S. W. Glyphosate influence on phytoplankton community structure in Lake Erie. J. Great Lakes Res. 2011, 37 (4), 683-690.

(24) Kononova, S. V.; Nesmeyanova, M. A. Phosphonates and their degradation by microorganisms. Biochemistry 2002, 67 (2), 184-195.

(25) Agarwal, V.; Borisova, S. A.; Metcalf, W. W.; Van Der Donk, W. A.; Nair, S. K. Structural and mechanistic insights into C-P bond hydrolysis by phosphonoacetate hydrolase. Chem. Biol. 2011, 18 (10), 1230-1240.

(26) Villarreal-Chiu, J. F.; Quinn, J. P.; McGrath, J. W., The genes and enzymes of phosphonate metabolism by bacteria, and their distribution in the marine environment. Front. Microbiol. 2012, 3, (JAN). DOI: $10.3389 /$ fmicb.2012.00019.

(27) Dyhrman, S. T.; Chappell, P. D.; Haley, S. T.; Moffett, J. W.; Orchard, E. D.; Waterbury, J. B.; Webb, E. A. Phosphonate utilization by the globally important marine diazotroph Trichodesmium. Nature 2006, 439 (7072), 68-71.

(28) Yao, M.; Henny, C.; Maresca, J. A. Freshwater bacteria release methane as a by-product of phosphorus acquisition. Appl. Environ. Microbiol. 2016, 82 (23), 6994-7003.

(29) Ulrich, M. M.; Mueller, S. R.; Singer, H. P.; Imboden, D. M.; Schwarzenbach, R. P. Input and Dynamic Behavior of the Organic Pollutants Tetrachloroethene, Atrazine, and NTA in a Lake: A Study Combining Mathematical Modeling and Field Measurements. Environ. Sci. Technol. 1994, 28 (9), 1674-85.

(30) Niederhauser, P.; Känel, B.; Meier, W.; Labhart, W.; Nyffenegger, K.; Balsiger, C. Wasserqualität der Seen, Fliessgewässer und des Grundwassers im Kanton Zürich; AWEL Amt für Abfall, Wasser, Energie und Luft: 2006.

(31) Reichert, P. Aquasim - A tool for simulation and data analysis of aquatic systems. Water Sci. Technol. 1994, 30 (2 pt 2), 21-30.

(32) Huntscha, S.; Singer, H.; Canonica, S.; Schwarzenbach, R. P.; Fenner, K. Input dynamics and fate in surface water of the herbicide metolachlor and of its highly mobile transformation product metolachlor ESA. Environ. Sci. Technol. 2008, 42 (15), 5507-5513.

(33) Meyer, F.; Paarmann, D.; D’Souza, M.; Olson, R.; Glass, E. M.; Kubal, M.; Paczian, T.; Rodriguez, A.; Stevens, R.; Wilke, A.; Wilkening, J.; Edwards, R. A. The metagenomics RAST server - A public resource for the automatic phylogenetic and functional analysis of metagenomes. BMC Bioinf. 2008, 9, 386.

(34) Nowack, B. Environmental chemistry of phosphonates. Water Res. 2003, 37 (11), 2533-2546.

(35) Stoll, J. M. A.; Ulrich, M. M.; Giger, W. Dynamic behavior of fluorescent whitening agents in Greifensee: Field measurements combined with mathematical modeling of sedimentation and photolysis. Environ. Sci. Technol. 1998, 32 (13), 1875-1881.

(36) Maqueda, C.; Undabeytia, T.; Villaverde, J.; Morillo, E. Behaviour of glyphosate in a reservoir and the surrounding agricultural soils. Sci. Total Environ. 2017, 593-594, 787-795.

(37) Poiger, T.; Buser, H. R.; Muller, M. D. Photodegradation of the pharmaceutical drug diclofenac in a lake: Pathway, field measurements, 
and mathematical modeling. Environ. Toxicol. Chem. 2001, 20 (2), 256-263.

(38) Hove-Jensen, B.; Zechel, D. L.; Jochimsen, B. Utilization of glyphosate as phosphate source: biochemistry and genetics of bacterial carbon-phosphorus lyase. Microbiol. Mol. Biol. Rev. 2014, 78 (1), 17697.

(39) Kutovaya, O. A.; McKay, R. M. L.; Bullerjahn, G. S. Detection and expression of genes for phosphorus metabolism in picocyanobacteria from the Laurentian Great Lakes. J. Great Lakes Res. 2013, 39 (4), $612-621$.

(40) Ternan, N. G.; Mc Grath, J. W.; Mc Mullan, G.; Quinn, J. P. Review: Organophosphonates: Occurrence, synthesis and biodegradation by microorganisms. World J. Microbiol. Biotechnol. 1998, 14 (5), 635-647.

(41) Brentrup, J. A.; Williamson, C. E.; Colom-Montero, W.; Eckert, W.; de Eyto, E.; Grossart, H. P.; Huot, Y.; Isles, P. D. F.; Knoll, L. B.; Leach, T. H.; McBride, C. G.; Pierson, D.; Pomati, F.; Read, J. S.; Rose, K. C.; Samal, N. R.; Staehr, P. A.; Winslow, L. A. The potential of high-frequency profiling to assess vertical and seasonal patterns of phytoplankton dynamics in lakes: An extension of the Plankton Ecology Group (PEG) model. Inland Waters 2016, 6 (4), 565-580.

(42) Barry, G. F.; Kishore, G. M. Glyphosate tolerant plants. US Patent No. 5,463,175, 1995.

(43) OECD, Test No. 308: Aerobic and Anaerobic Transformation in Aquatic Sediment Systems; OECD Publishing, 2002.

(44) OECD, Test No. 309: Aerobic Mineralisation in Surface Water Simulation Biodegradation Test; OECD Publishing, 2004.

(45) Forlani, G.; Bertazzini, M.; Giberti, S.; Wieczorek, D.; Kafarski, P.; Lipok, J. Sublethal detergent concentrations increase metabolization of recalcitrant polyphosphonates by the cyanobacterium Spirulina platensis. Environ. Sci. Pollut. Res. 2013, 20 (5), 3263-3270. 